\title{
Efficacy of systematic voice training combined with swallowing function exercises for the prevention of swallowing dysfunction in stroke patients: a retrospective study
}

\author{
Xiaoping Ren ${ }^{1 \#}$, Lidan Huang ${ }^{2 \#}$, Jie Wang $^{3}$, Jianxia He $^{4}$, Xiuli Bai ${ }^{4}$, Yan $\mathrm{He}^{4}$ \\ ${ }^{1}$ Department of Rehabilitation, Affiliated Hangzhou First People's Hospital, Zhejiang University School of Medicine, Hangzhou, China; \\ ${ }^{2}$ Department of Anesthesiology, Renmin Hospital of Wuhan University, Wuhan, China; ${ }^{3}$ Department of Neurology, Baotou Central Hospital, \\ Baotou, China; ${ }^{4}$ Department of Nursing, Baotou Central Hospital, Baotou, China \\ Contributions: (I) Conception and design: X Ren, Y He; (II) Administrative support: X Ren, L Huang, Y He; (III) Provision of study materials or \\ patients: X Ren, J Wang; (IV) Collection and assembly of data: X Bai, L Huang, J Wang, J He; (V) Data analysis and interpretation: L Huang; (VI) \\ Manuscript writing: All authors; (VII) Final approval of manuscript: All authors. \\ "These authors contributed equally to this work. \\ Correspondence to: Yan He. Department of Nursing, Baotou Central Hospital, No. 61 Huancheng Road, Donghe District, Baotou, China. Email: \\ heyanbt@sina.com.
}

Background: Stroke is a common clinical brain disease, and swallowing dysfunction is one of the most common complications in stroke patients. Despite multiple treatments for swallowing dysfunction, it often leads to a series of complications. Interventions such as systematic voice training and swallowing function exercises have emerged in recent years, but their effectiveness remains unclear. Therefore, this study was conducted to investigate the effect of systematic voice training combined with swallowing function exercise for the prevention of swallowing dysfunction and improving the quality of life of stroke patients.

Methods: We retrospectively analyzed 90 stroke patients admitted to Baotou Central Hospital from October 2018 to October 2021 as study subjects, and divided the patients into a combined voice training group $(n=45)$ and a single swallowing exercise group $(n=45)$ according to the interventions. The single swallowing exercise group received routine swallowing function exercise, and the combined voice training group used systematic voice training combined with swallowing function exercise. The incidence of swallowing dysfunction, malnutrition, aspiration pneumonia, and exercise compliance rate were compared between the two groups, and the quality of life of the two groups was evaluated by the Generic Quality of Life Inventory 74 (GQOLI-74) before and after the interventions, respectively.

Results: The incidence of swallowing dysfunction, aspiration pneumonia, and malnutrition were lower in the combined voice training group than in the single swallowing exercise group $(\mathrm{P}<0.05)$, and there was no statistically significant difference in the exercise compliance rate between the two groups. The combined voice training group had higher psychological dimensions, physical dimensions, social adaptation, and total quality of life scores than the single swallowing exercise group (all $\mathrm{P}<0.05$ ). Compared with the conventional intervention group, the combined voice training group had higher patient satisfaction $(\mathrm{P}<0.05)$.

Conclusions: Systematic voice training combined with swallowing function exercise can effectively prevent the occurrence of swallowing dysfunction and improve the quality of life of patients with stroke.

Keywords: Stroke; systematic voice training; swallowing function exercise; swallowing dysfunction

Submitted Nov 08, 2021. Accepted for publication Feb 16, 2022.

doi: $10.21037 /$ atm-22-101

View this article at: https://dx.doi.org/10.21037/atm-22-101 


\section{Introduction}

With the improvement of people's living standard in recent years, the incidence of cerebrovascular diseases, diabetes, hypertension, and other diseases has exhibited an increasing trend $(1,2)$. As a common clinical brain disease, stroke has high rates of mortality and disability. Swallowing dysfunction is a common complication in stroke patients, which is mainly manifested in dysphonia, cough, difficulty eating, and other symptoms. The pathogenesis of Swallowing dysfunction after stroke may be related to the following factors: cerebral cortex injury, swallowing nerve injury and bulbar swallowing center injury. Currently, there are many clinical treatments for post-stroke swallowing dysfunction, such as respiratory muscle training (3) and medications, but a series of complications often occur in clinical treatment, and certain clinical interventions are required. Psychological intervention may also have a positive effect on post-stroke swallowing dysfunction patients, but there is a lack of relevant research.

Interventions such as systematic voice training and swallowing function exercises have emerged in recent years, among which voice training can guide patients to enhance their pharyngeal muscle endurance and improve their voice quality, with the help of scientific and systematic relaxation and breathing $(4,5)$. However, the data of efficacy of systematic voice training combined with swallowing function exercises for the prevention of swallowing dysfunction in stroke patients is lack. In this study, we used systematic voice training combined with swallowing function exercises for patients with post-stroke swallowing dysfunction, aiming to explore the clinical effect of the two combined interventions on patients with swallowing dysfunction after stroke.

We present the following article in accordance with the STROBE reporting checklist (available at https://atm. amegroups.com/article/view/10.21037/atm-22-101/rc).

\section{Methods}

\section{Materials}

Stroke, systematic voice training, swallowing dysfunction were used as search terms. The exclusion criteria were as follows: (I) non-first-episode patients with severe motor dysfunction; (II) patients with aphasia or impaired consciousness; (III) patients aged $>75$ years; and (IV) those combined with serious complications in other systems. The inclusion criteria were as follows: (I) the diagnosis was confirmed by CT and MRI according to the diagnostic criteria of the $4^{\text {th }}$ National cerebrovascular disease academic conference (6); (II) no swallowing dysfunction; (III) patients determined to have normal cognitive function by two or more neurologists, and can voluntarily complete all tests and rehabilitation training (7); and (IV) those aged 50-75 years.

We performed a retrospective analysis of 90 stroke patients admitted to Baotou Central Hospital from October 2018 to October 2021, and the patients were divided into single swallowing exercise group and combined voice training group. There were 45 stroke patients (aged 58-71) years in the single swallowing exercise group and 45 stroke patients (aged 56-70 years) in the study group. As shown in Table 1, there was no statistical difference between the general data of the two groups of patients and they were comparable. All procedures performed in this study involving human participants were in accordance with the Declaration of Helsinki (as revised in 2013). The study was approved by the Ethics Committee of Baotou Central Hospital (Approval No. 2021-078). Individual consent for this retrospective analysis was waived.

\section{Treatment method}

Both groups of patients received conventional nursing treatment, including introducing the hospital environment and providing knowledge of the disease to patients. The single swallowing exercise group performed a single swallowing function exercise, including articulation training, pharyngeal perception training, and empty swallowing training. Articulation training involved slowly pronouncing a word such as "yah", "ah", etc. five times (once before breakfast, lunch, and dinner). Oral pharyngeal perception training was performed once in the morning and once in the afternoon, and involved a paste being placed on the side of the mouth and the patients encouraged to swallow it by themselves. Empty swallow training was performed or three times before each meal. At the same time, training was carried out with as little patient conversation as possible to avoid increased difficulty in swallowing.

The combined voice training group performed systematic voice training based on the single swallowing exercise group, which was divided into three stages (1 week in each stage). In the first stage, in order to relieve the patients' muscle tension, the relaxation training of articulatory organs was initially carried out, with semi-closed vocal tract exercises. The patients' lips were relaxed to the vocal folds with lightly closed to toothed lips situation, and after 
Table 1 Comparison of baseline information of patients in the combined voice training and single swallowing exercise groups

\begin{tabular}{|c|c|c|c|c|c|c|}
\hline Groups & Mean age (y) & $\begin{array}{l}\text { Course of } \\
\text { disease (d) }\end{array}$ & \multicolumn{2}{|c|}{ Gender } & \multicolumn{2}{|c|}{ Type of stroke } \\
\hline Combined voice training group (45 cases) & $52.5 \pm 6.3$ & $3.2 \pm 1.3$ & 29 & 16 & 30 & 15 \\
\hline Single swallowing exercise group (45 cases) & $53.8 \pm 7.2$ & $3.4 \pm 1.1$ & 27 & 18 & 26 & 19 \\
\hline$t / \chi^{2}$ & -0.912 & -0.788 & \multicolumn{2}{|c|}{0.189} & \multicolumn{2}{|c|}{0.756} \\
\hline
\end{tabular}

deep inhalation, the airflow was exhaled to keep the regular tremor of the lips. Next, throat relaxation training was performed by yawning and deep inhalation at the same time to relax the throat muscles (with each training period lasting $10 \mathrm{~min}$ ), and then adjusted according to the patients' condition (five times daily for 1 week).

In the second stage, to improve muscle function, the patients performed deep inhalation in a lying position with the body in a relaxed state, and exhalation in a smooth and sustained manner, while encouraging the patient to increase moderate abdominal strength with exercises such as sit-ups. Patients stood with their arms crossed and leaned forward, stuck out their tongues, and started to swing their heads so that their tongues touched the corners of the mouth on both sides as much as possible. Each training session lasted for $10 \mathrm{~min}$ and was later adjusted according to the patient's condition, and was performed five times a day for 1 week.

In the third stage, to improve the movement of the vocal cords, the medical staff asked the patient to relax the upper body and make resonant vocalizations. The patient felt the articulation process with both hands on both sides of the cheeks, so that they could feel the resonance of the nasal cavity. And this was performed two times a day for 1 week.

The whole treatment cycle was three weeks, and the curative effect was evaluated at the end of the treatment.

\section{Swallowing function recovery evaluation}

The recovery of swallowing function was compared between the two groups using the Water Swallow Test (WST) and the Standardized Swallowing Assessment (SSA). The SSA involves mental awareness, breathing pattern, and swallowing motor status. The presence of swallowing dysfunction was determined when the score was higher than 30. Also, malnutrition, aspiration pneumonia, and exercise compliance rate of patients were professionally recorded and compared by our physicians.

\section{Survival quality evaluation}

The quality of survival before and after the intervention was assessed by the Generic Quality of Life Inventory 74 (GQOLI-74), and the quality of survival in both groups was evaluated in three dimensions: psychological dimension, physical dimension, and social adaptability, each with a score of 100 . The score was directly proportional to the quality of survival, with higher quality of survival resulting in higher scores, and the overall quality of survival score was averaged across the three dimensions.

\section{Statistical analysis}

IBM SPSS 21.0 software was selected for processing. Counting data were expressed as a percentage (\%), and the comparison between groups was tested by the $\chi^{2}$ test. Measurement data were described by $\left(\bar{x}_{ \pm \mathrm{s}}\right)$, and the comparison between groups was tested by the least significant difference $t$-test. $\mathrm{P}<0.05$ was considered to indicate a statistically significant difference.

\section{Results}

\section{Comparison of baseline information}

As shown in Table 1, there was no significant difference $(\mathrm{P}>0.05)$ between the two groups in terms of mean age, disease duration, gender, and other baseline information, which were comparable.

\section{Comparison of swallowing dysfunction, malnutrition, aspiration pneumonia and exercise adberence rate}

The whole treatment cycle was three weeks, and the 
Table 2 Comparison of swallowing dysfunction, malnutrition, aspiration pneumonia and exercise compliance rates between the two groups

\begin{tabular}{|c|c|c|c|c|c|c|c|c|}
\hline \multirow[t]{2}{*}{ Groups } & \multicolumn{2}{|c|}{$\begin{array}{l}\text { Swallowing } \\
\text { dysfunction }\end{array}$} & \multicolumn{2}{|c|}{ Malnutrition } & \multicolumn{2}{|c|}{$\begin{array}{l}\text { Aspiration } \\
\text { pneumonia }\end{array}$} & \multicolumn{2}{|c|}{$\begin{array}{c}\text { Exercise } \\
\text { compliance rates }\end{array}$} \\
\hline & Yes & No & Yes & No & Yes & No & Yes & No \\
\hline Single swallowing exercise group (45 cases) & 10 & 35 & 9 & 36 & 8 & 37 & 39 & 6 \\
\hline$\chi^{2}$ & \multicolumn{2}{|c|}{6.154} & \multicolumn{2}{|c|}{7.200} & \multicolumn{2}{|c|}{$4.444^{\mathrm{a}}$} & \multicolumn{2}{|c|}{$1.235^{\mathrm{a}}$} \\
\hline
\end{tabular}

${ }^{\mathrm{a}}$, is the result of continuity correction, and the rest are all cardinality tests.

Table 3 Evaluation of the quality of survival before and after intervention in both groups $\left(\bar{x}_{ \pm} \mathrm{s}\right)$

\begin{tabular}{lcccc}
\hline Groups & $\begin{array}{c}\text { Psychological } \\
\text { dimensions }\end{array}$ & $\begin{array}{c}\text { Physiological } \\
\text { dimensions }\end{array}$ & $\begin{array}{c}\text { Social } \\
\text { adaptability }\end{array}$ & $\begin{array}{c}\text { Total quality of } \\
\text { survival scores }\end{array}$ \\
\hline Combined voice training group (pre) & $57.25 \pm 3.36$ & $59.36 \pm 3.96$ & $57.14 \pm 3.89$ & $58.22 \pm 4.69$ \\
Single swallowing exercise group (pre) & $57.36 \pm 3.28$ & $59.23 \pm 4.02$ & $56.96 \pm 4.02$ & $58.69 \pm 4.29$ \\
Combined voice training group (post) & $79.38 \pm 3.26$ & $71.09 \pm 2.98$ & $74.08 \pm 3.11$ & $63.26 \pm 2.88$ \\
Single swallowing exercise group (post) & $60.63 \pm 1.25$ & $66.46 \pm 2.02$ & 20.16 & $69.56 \pm 2.04$ \\
T-value after intervention in both groups & 34.84 & 9.285 & $<0.001$ & $<.741$ \\
P value after intervention in both groups & $<0.001$ & $<0.001$ & $<0.001$ \\
\hline
\end{tabular}

curative effect was evaluated at the end of the treatment. As shown in Table 2, the incidence of swallowing dysfunction, malnutrition, and aspiration pneumonia was significantly lower post-intervention in the combined voice training group than in the single swallowing exercise group, and the differences were statistically significant. However, there was no significant difference in the exercise compliance rates between the two groups $(\mathrm{P}>0.05)$.

\section{Evaluation of survival quality}

As shown in Table 3 and Figures 1-4, there were no significant difference between the two groups in terms of psychological dimensions, physiological dimensions, social adaptability, and total quality of survival scores before the intervention $(\mathrm{P}>0.05)$. After the intervention, the combined voice training group had significantly higher psychological dimensions, physiological dimensions, social adaptability, and total quality of survival scores than the single swallowing exercise group $(\mathrm{P}<0.05)$.

\section{Comparison of family satisfaction}

As shown in Table 4, after the intervention, the satisfaction rate of patients in both groups was higher in the combined voice training group compared with the conventional intervention group, with a significant difference $(\mathrm{P}<0.05)$.

\section{Discussion}

Stroke is a common cerebrovascular disease in the elderly. Swallowing dysfunction is the most common complication in stroke patients, and is also a risk factor for depression and malnutrition (8). Currently, stroke swallowing dysfunction is caused by bilateral cortical brainstem tract damage or medulla oblongata paralysis after stroke, which leads to pseudo-medulla oblongata paralysis. This leads to damage to the glossopharyngeal nerve and reduces the swallowing function of patients. Clinical rehabilitation and pharmacotherapy are less effective as common clinical treatments for stroke swallowing dysfunction $(9,10)$, which highlights the importance of interventions.

Swallowing function exercise is mainly carried out using the reference neuronal remodeling and nerve promotion techniques; when a patient develops swallowing dysfunction, passive and active control training of the esophageal muscles and mouth are used to achieve muscle coordination 


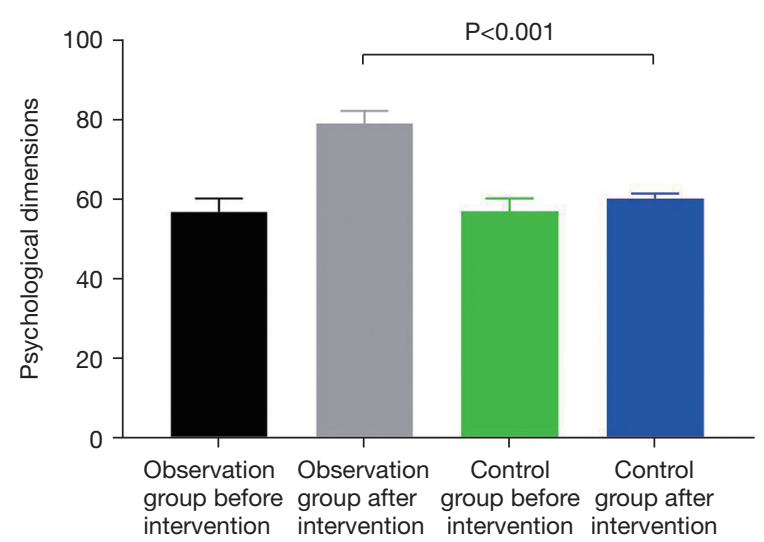

Figure 1 Comparison of psychological dimensions between the two groups before and after intervention.

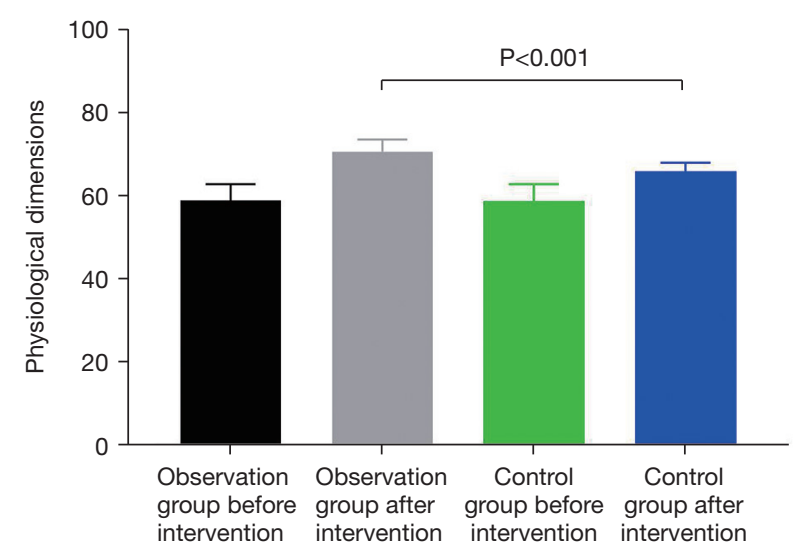

Figure 2 Comparison of physiological dimensions between the two groups before and after intervention.

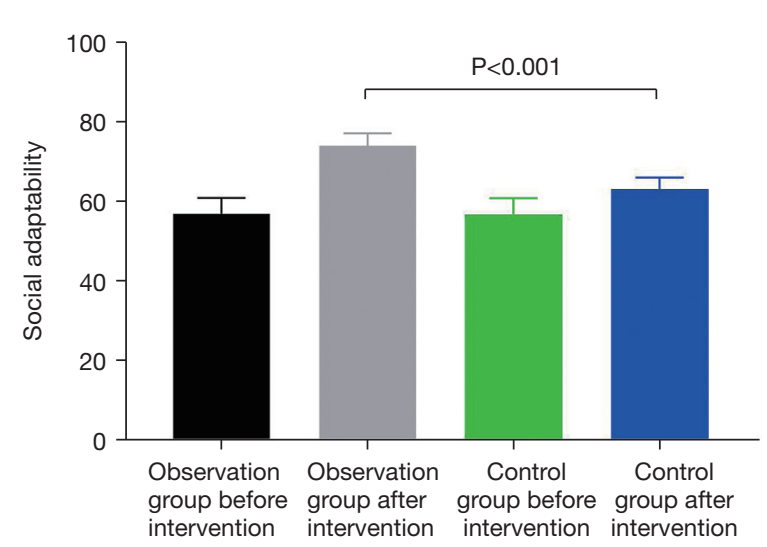

Figure 3 Comparison of the social adaptability between the two groups before and after intervention.

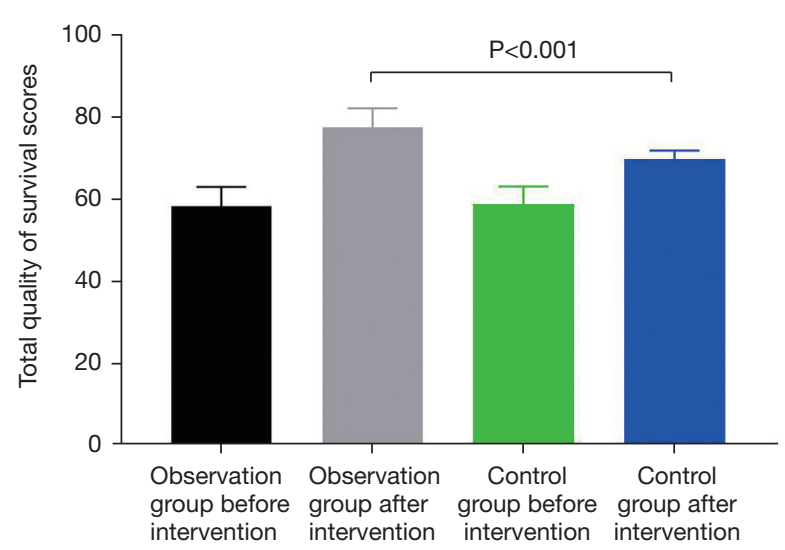

Figure 4 Comparison of the total quality of survival scores between the two groups before and after intervention.

Table 4 Comparison of the satisfaction rate of patients' families in the two groups $(\mathrm{N}, \%)$

\begin{tabular}{|c|c|c|c|c|c|}
\hline Groups & Number of cases & Very satisfied & Satisfied & Dissatisfied & Satisfaction rate \\
\hline Single swallowing exercise group & 45 & 21 & 16 & 8 & 37 (82.22) \\
\hline$\chi^{2}$ & & & & & 4.051 \\
\hline$P$ value & & & & & 0.044 \\
\hline
\end{tabular}

and flexibility $(11,12)$. With improvement of the esophageal muscles, the patient's blood circulation in the swallowing trachea can be improved, as well as enhancing the sensitivity of the central nervous system to the patient's swallowing function and strengthen the swallowing reflex $(13,14)$.

Systematic voice training focuses on relieving the patient's muscle tension and enhancing the mucosal wave and amplitude of the patient's vocal cord vibration, which in turn leads to relaxation and muscle control. It can also mobilize the patient's diaphragm activity, increase the their lung storage capacity, and improve their vocal continuity and stability with the help of functional training of the tongue root laryngeal muscles $(15,16)$. When the vocalization is more stable, the vocal cord movements of patients are improved, 
including whisper-like vocalization and resonant vocalization. The psychological status of patients is closely related to the treatment effect during the treatment process. If patients lose confidence in treatment and have serious anxiety and depression, it will make the treatment more difficult, and at the same time, the prognosis of these patients is poor $(17,18)$. Therefore, it is important to improve the psychological situation of patients. In this study, it was found that systematic voice training combined with swallowing function exercises improved the psychological and physiological dimensions of patients with stroke swallowing dysfunction, which suggests that systematic voice training combined with swallowing function exercises can improve the psychological condition of patients and thereby improve their physiological dimensions.

In the early stages of the disease, physicians pay greater attention to the progression of the patient's condition, and the patients themselves do not have a comprehensive perception of physical pain. Therefore, timely and effective interventions are particularly important to improve the social adaptation and the quality of survival of patients with stroke-induced swallowing dysfunction (19). A clinical study has shown that the use of better intervention methods for stroke patients with swallowing dysfunction can lead to an effective intervention effect (20). In this study, it was found that the use of systematic voice training combined with swallowing function exercises for stroke patients resulted in a greater improvement in the patients' social adjustment and total quality of life scores. It could also be seen that systematic voice training combined with swallowing function exercise can have a better intervention effect on patients by improving their voice and laryngeal muscles, which can in turn effectively improve their overall survival quality score. Systematic voice training combined with swallowing function exercise can stimulate afferent nerves, and then stimulate upper motor neurons to promote the recovery of swallowing function.

\section{Conclusions}

In conclusion, systematic voice training combined with swallowing function exercise in stroke patients with swallowing dysfunction improved swallowing dysfunction and malnutrition, and enhanced the quality of survival by improving the patient's voice and laryngeal muscles, which had a good intervention effect $(15,16)$.

\section{Limitations}

The number of cases in this study was relatively insufficient.
Therefore, it is impossible to conduct stratified research according to age and gender. Although it was found in this study that systematic voice training combined with swallowing function exercise in stroke patients could effectively improve the quality of survival, the number of cases selected in this study was small, and the study has certain limitations, which may lead to some deviations in the results. Thus, a large number of samples are needed in future studies to confirm our findings and formulate precise intervention measures.

\section{Acknowledgments}

Funding: Hangzhou Health Science and Technology PlanProject: Construction and Empirical Study of the Selfmanagement Scheme of Stroke Patients with Dysphagia Based Evidence (A20210300).

\section{Footnote}

Reporting Checklist: The authors have completed the STROBE reporting checklist. Available at https://atm. amegroups.com/article/view/10.21037/atm-22-101/rc

Data Sharing Statement: Available at https://atm.amegroups. com/article/view/10.21037/atm-22-101/dss

Conflicts of Interest: All authors have completed the ICMJE uniform disclosure form (available at https://atm. amegroups.com/article/view/10.21037/atm-22-101/coif). The authors have no conflicts of interest to declare.

Ethical Statement: The authors are accountable for all aspects of the work in ensuring that questions related to the accuracy or integrity of any part of the work are appropriately investigated and resolved. All procedures performed in this study involving human participants were in accordance with the Declaration of Helsinki (as revised in 2013). The study was approved by the Ethics Committee of Baotou Central Hospital (Approval No. 2021-078). Individual consent for this retrospective analysis was waived.

Open Access Statement: This is an Open Access article distributed in accordance with the Creative Commons Attribution-NonCommercial-NoDerivs 4.0 International License (CC BY-NC-ND 4.0), which permits the noncommercial replication and distribution of the article with the strict proviso that no changes or edits are made and the original work is properly cited (including links to both the 
formal publication through the relevant DOI and the license). See: https://creativecommons.org/licenses/by-nc-nd/4.0/.

\section{References}

1. Pranata R, Huang I, Lim MA, et al. Impact of cerebrovascular and cardiovascular diseases on mortality and severity of COVID-19-systematic review, meta-analysis, and meta-regression. J Stroke Cerebrovasc Dis 2020;29:104949.

2. Maida CD, Norrito RL, Daidone M, et al. Neuroinflammatory Mechanisms in Ischemic Stroke: Focus on Cardioembolic Stroke, Background, and Therapeutic Approaches. Int J Mol Sci 2020;21:6454.

3. Zhang W, Pan H, Zong Y, et al. Respiratory Muscle Training Reduces Respiratory Complications and Improves Swallowing Function After Stroke: A Systematic Review and Meta-Analysis. Arch Phys Med Rehabil 2021. doi: 10.1016/j.apmr.2021.10.020.

4. Dionísio A, Duarte IC, Patrício M, et al. Transcranial Magnetic Stimulation as an Intervention Tool to Recover from Language, Swallowing and Attentional Deficits after Stroke: A Systematic Review. Cerebrovasc Dis 2018;46:178-85.

5. Hao H, Bai JY, Li L, et al. Analysis on the effect of voice training and voice hygiene education in the treatment of vocal nodule. Chin J Otorhinolaryngol Integ Med 2019;27:268-71.

6. Chinese Society of Neurology, Chinese Society of Neurology, Cerebrovascular Group. Chinese guidelines for diagnosis and treatment of acute ischemic stroke 2018. Chin J Neuro 2018;51:666-82.

7. Chen RY, Liu Y, Sun T, et al. The effect of lung exercise on respiratory and motor function, life quality and the survival of patients with non-operative lung cancer. Chin J Physic Med and Rehabi 2019;41:31-6.

8. Hägglund P, Hägg M, Levring Jäghagen E, et al. Oral neuromuscular training in patients with dysphagia after stroke: a prospective, randomized, open-label study with blinded evaluators. BMC Neurol 2020;20:405.

9. Park KD, Kim TH, Lee SH. The Gugging Swallowing Screen in dysphagia screening for patients with stroke: A systematic review. Int J Nurs Stud 2020;107:103588.

10. Juan W, Zhen H, Yan-Ying F, et al. A Comparative Study of Two Tube Feeding Methods in Patients with Dysphagia After Stroke: A Randomized Controlled Trial. J Stroke Cerebrovasc Dis 2020;29:104602.

11. Alamer A, Melese H, Nigussie F. Effectiveness of Neuromuscular Electrical Stimulation on Post-Stroke Dysphagia: A Systematic Review of Randomized
Controlled Trials. Clin Interv Aging 2020;15:1521-31.

12. Balou M, Herzberg EG, Kamelhar D, et al. An intensive swallowing exercise protocol for improving swallowing physiology in older adults with radiographically confirmed dysphagia. Clin Interv Aging 2019;14:283-8.

13. Carnaby GD, LaGorio L, Silliman S, et al. Exercise-based swallowing intervention (McNeill Dysphagia Therapy) with adjunctive NMES to treat dysphagia post-stroke: A double-blind placebo-controlled trial. J Oral Rehabil 2020;47:501-10.

14. He DJ, Cui Y, Tang JY, et al. Prevention and treatment of respiratory crisis after general anesthesia in otorhinolaryngology head and neck surgery. J Prev Med Chin PLA 2019;37:184-5.

15. Chen SQ, Jiang HB, Han PP, et al. Effect of early deglutition training exercise on deglutition dysfunction after cerebellopontine Angle tumor. Chin J Clin Oncol Rehabil 2020;27:1085-8.

16. Peng J, Li XH, Zou M, et al. Effect of Voice Training on Vocal Function for Patients with Early Vocal Fold Polyps. Chin J Rehabil Theory Pract 2020;26:936-40.

17. Yang JY, Zhong YP, Lu WM. Effect of voice training combined with psychological intervention on improving anxiety and depression in patients with voice diseases. China Modern Medicine 2020;27:194-6.

18. Liang FQ, Wang LF, Tian L, et al. Press Needle Combined with Voice Therapy Treating Benign Vocal Fold Lesions: A Randomized Controlled Trial. Chinese Journal of Integrated Traditional and Western Medicine 2020;40:685-90.

19. Liu XL, Li MH, Zhou SD, et al. Changes of the Voice Range Profile and Acoustic Parameters before and after Vocal Training for Professional Voice User. Journal of Audiology and Speech Pathology 2020;28:24-7.

20. Wang YD, Zhang T. Effect of swallowing function training on dysphagia in stroke patients. Neural Iniurv And Functional Reconstruction 2019;14:263-5.

(English Language Editor: A. Kassem)

Cite this article as: Ren X, Huang L, Wang J, He J, Bai X, He Y. Efficacy of systematic voice training combined with swallowing function exercises for the prevention of swallowing dysfunction in stroke patients: a retrospective study. Ann Transl Med 2022;10(4):195. doi: 10.21037/atm-22-101 